\title{
Perceived Social Benefits, Effects of Cigarette Smoking and Alcoholic Beverages Consumption on Nutritional Status of Road Transport Workers in Lagos
}

\author{
${ }^{1}$ Mustapha R.A., ${ }^{2}$ Bolajoko O.O., ${ }^{3}$ Hammed I.A., ${ }^{4}$ Akinola O.O. \\ ${ }^{1,2}$ Department of Nutrition and DieteticsRufus Giwa Polytechnic, PMB 1019, Owo, Ondo State. \\ ${ }^{3,4}$ Department of Nutrition and DieteticsFederal Polytechnic Ede,PMB 155, Ede, Osun State.
}

\begin{abstract}
Background: The influence of cigarette smoking and alcoholic beverages consumption on health and nutrient intake and its effect on metabolic processes has been well elucidated in the literature.

Objective: This study was carried out to evaluate the perceived benefits and effects of cigarette smoking and alcohol consumption on nutritional status of road transport workers in Lagos State, Nigeria.

Method: A total of 205 male transport workers were selected using quota and random sampling method. Socioeconomic data and dietary intake, cigarette smoking and alcohol consumption pattern were assessed using pretested interviewer administered questionnaire, 24 hour dietary recall and anthropometry protocol.

Results: Findings show that their mean age and weight were 32.8 years and $64 \mathrm{~kg}$ respectively. The mean energy and protein intake were $2029 \mathrm{kcal} /$ day and 81.7g/day. Energy intake met only 70\% of RDA but alcohol was found to significantly $(P<0.05)$ affect the intake of energy giving nutrients. Also intake of micronutrients such as calcium, iron, vitamin $B_{2}$ and vitamin $B_{3}$ were all lower than their RDA. $51.2 \%$ of the subjects were cigarette smokers and alcoholics. Different reasons were perceived by subjects for cigarette smoking and alcohol consumption, which includes boosting sexual power (35\%), suppressed cold (56.8\%), increased confidence (29.4\%), taken for fun (43.2\%), prevents sleeping at work (24.8\%), and boosting of energy at work (35.6\%). Smoking and alcohol consumption significantly affect their BMI $(P<0.05)$ and $30.8 \%$ of the subjects were underweight, $18 \%$ were overweight, while $3.9 \%$ were obese.

Conclusion: Cigarette smoking and alcohol consumption impaired appetite, nutrient utilization and bioavailability, energy intake and bring about future health problems.

Keywords: Alcohol, Cigarette smoking, nutrient consumption, perceived benefits.
\end{abstract}

\section{Introduction}

Alcohol is a narcotic, an agent that reduces sensation and consciousness, and a central nervous system depressant. While cigarette smoking is a highly pervasive personal habit, with a strong appeal among teenagers and young adults ${ }^{(1,17,19)}$. For centuries, smokers and alcoholics often perceived that these substances relieve feelings of stress, depression, a sense of belonging, increase confidence and mental concentration ${ }^{(2,3)}$.

However, studies have shown that smoking and alcoholism are social insolence which are predictor to household violence, divorce, various crimes and juvenile delinquencies ${ }^{(3,4)}$. The harmful effects of alcohol are well known. Too much alcohol damages almost every organs in the body. The liver and brain are especially vulnerable to its toxic effects. A complex interplay exist between a person's alcohol consumption and nutritional status ${ }^{(5,18)}$.

Research has also confirmed that, one hour exposure to cigarette smoke for two months significantly decreased the body weight and food intake in male and female albino rats ${ }^{(6,7)}$. Many people, including high-tomoderate drinkers who consume one to two glasses or less of an alcoholic beverage per day, consider those beverages as part of their normal diet and acquire a certain number of calories from them. When consumed in excess, however, alcohol can cause disease by interfering with the nutritional status of the drinkers. In addition, alcohol exerts some harmful effects through its breakdown (metabolism) and the resulting toxic compound, particularly in the liver where most of the alcohol metabolism occur ${ }^{(7,20,21)}$.

There are various studies particularly from developed countries on the effects of alcohol or cigarette on nutrient intake of their population ${ }^{(1,3,4)}$. Information and studies on perceived social benefits and effect of cigarette and alcoholic drinks on nutritional status in Lagos and in Nigeria as a whole is minimal and scanty. Therefore this study assessed the perceived social benefits, effects of cigarette and alcoholic beverages consumption on nutritional status of National Union of Road Transport Workers in Lagos, Nigeria.

\section{Materials And Methods}

This study was carried out between June 2010 and April 2011, in randomly selected urban metropolitan centres of Lagos. The study was carried out among members of National Union of Road Transport Workers, 
which includes motor bike (okada) riders, motor drivers and conductors. Random sampling method was used to select densely populated areas with Government-owned metro-bus drivers and private cab drivers. Some of the areas selected for the study include Oshodi, Yaba, Mile 2, Idumota, Okokomaiko, Iyana-Ipaja, Agege, Ojota, Oyingbo and Ikeja. An average of two hundred and five (205) subjects were randomly selected using quota system based on the population of members registered at each park of the Union centres located all around Lagos. Virtually, all members of the Road Transport Workers' Union were male, and therefore all subjects selected for this study were adult males.

\section{Ethical Consideration and Informed Consent}

The study was approved by the Lagos State Road Transport Union Executives, while written informed consent was obtained from the drivers and transport workers in each of the areas visited.

\section{Data Collection}

Questionnaire, anthropometry and 24-hour dietary recall protocol were the research instruments used in data collection in this study. Well structured and pre-tested interviewer administered questionnaire was used to assess the rate of alcohol intake, rate of cigarette smoking, type of alcoholic beverage taken, quantity of alcohol intake, usual daily income, reason for smoking, reason for drinking alcohol. While 24-hour dietary recall was used to estimate daily intake of all subjects. The questionnaire was administered for seven consecutive days equivalent to one week. Data on food and fluid intake was obtained using household measuring utensils and market prices to estimate amount of intake. Information on anthropometric measurement were also collected through standard procedure ${ }^{(8,9)}$.

\section{Data Analysis}

Means macronutrients (protein, carbohydrate and fat), energy, and micronutrients (calcium, iron, vitamin $B_{1}$, vitamin $B_{2}$ and vitamin $B_{3}$ ) intake of respondents were calculated using food composition table ${ }^{(10,12,13)}$. Mean height, weight and age were also determined. Both quantitative and socioeconomic data was analyzed using SPSS software (version 16.0) to determine mean, standard deviation, and percentages. T-test was used to test for statistical significance of anthropometric parameters and nutrients intakes, while socioeconomic data are subjected to Chi-square test.

\section{Results}

The categorization of respondents shown in figure 1 indicated that quite over $170(86.4 \%)$ of the subjects regularly consumed alcoholic beverages. While 109 (53.2\%) of the subjects were smokers of different types of cigarettes, $46.8 \%$ of the respondents were non-smokers. However, $51.2 \%$ were both cigarette smokers and regular consumers of various types of alcoholic beverages.

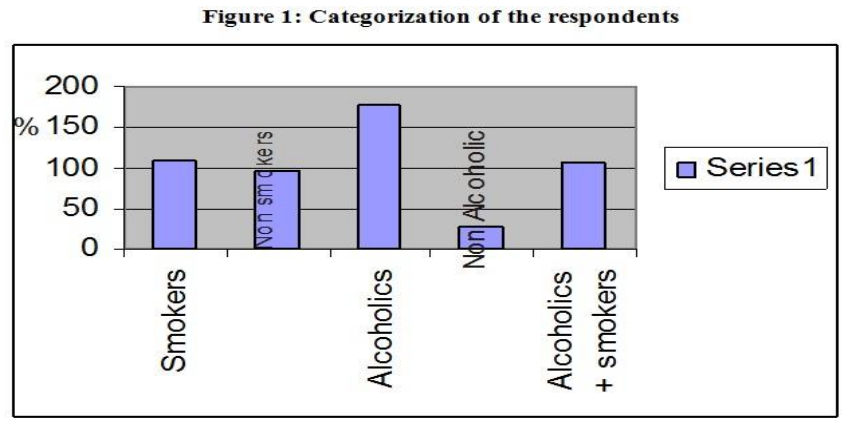

Shown in the result in table 1 were the perceived reasons for drinking alcohol and alcoholic beverages. Among the subjects those who said boosting of sexual power and energy to work were 30.2 and $30.7 \%$ respectively. While 25.4 and $7.3 \%$ out of the 205 subjects interviewed said alcohol increases their confidence and it suppresses cold. Only $2.9 \%$ said alcoholic beverages consumption was taken for fun. None of the respondents said they consume alcoholic beverages as a food that will supply nutrients.

Table 1: Perceived reasons for drinking alcohol.

\begin{tabular}{lll}
\hline Perceived Benefits of Alcohol & n & \% \\
\hline It boosts sexual power & 62 & 30.2 \\
It increases confidence & 52 & 25.4 \\
It boost energy to work & 63 & 30.7 \\
It suppresses cold & 15 & 7.3 \\
Taken for fun & 6 & 2.9 \\
Indifferent & 7 & 3.4 \\
\hline
\end{tabular}

$(n=205)$ 
Perceived Social Benefits, Effects Of Cigarette Smoking And Alcoholic Beverages Consumption On

The perceived social reasons why most of the respondents said they smoke cigarettes (table 2) was that it suppresses cold (30.2\%), just for fun (22.9\%), prevents sleeping when driving (24.9\%), and boosting of confidence $(15.6 \%)$.

Table 2: Perceived reasons for smoking

\begin{tabular}{lcl}
\hline Perceived Reasons for Smoking & n & \% \\
\hline It suppresses cold & 62 & 30.2 \\
Just for fun & 47 & 22.9 \\
Prevents sleeping & 51 & 24.9 \\
It boosts confidence & 32 & 15.6 \\
Indifferent & 13 & 6.3 \\
\hline
\end{tabular}

$(\mathrm{n}=205)$

The daily nutrients and energy intake of all the subjects was also assessed (table 3 and table 4). It was discovered that the mean macronutrients like protein $(81.75 \mathrm{~g} / \mathrm{d})$ and carbohydrate $(517.8 \mathrm{~g} / \mathrm{d})$ met over $100 \%$ of their Recommended Daily Allowance (RDA). However, the daily fat intake was quite lower (113g/day) than their RDA.

Table 3: Macronutrients and Energy intake of the subjects.

\begin{tabular}{llll}
\hline Macronutrients & Mean+SD & *RDA & \% RDA met \\
\hline Energy (kcal/day) & $2029 \pm 631.0$ & 2900 & 70 \\
Energy (MJ/day) & $8.481 \pm 1.2$ & 12.1 & 70 \\
Protein (g/day) & $81.75 \pm 37.6$ & 60 & 136 \\
Fat (g/day) & $66.45 \pm 47.4$ & 113 & 58 \\
Carbohydrate (g/day) & $517.86 \pm 69.7$ & 363 & 142 \\
\hline
\end{tabular}

$(\mathrm{n}=205) *(10,11)$

Table 4: Micronutrients intake of the subjects.

\begin{tabular}{llll}
\hline Micronutrients & Mean \pm SD & *RDA & \% RDA met \\
\hline Calcium (mg/day) & $401.31 \pm 195.4$ & 1000 & 40 \\
Iron (mg/day) & $8.07 \pm 1.3$ & 10 & 80.7 \\
Vitamin B $B_{1}(\mathrm{mg} /$ day) & $0.91 \pm 0.1$ & 1.2 & 75.8 \\
Vitamin $B_{2}$ (mg/day) & $1.74 \pm 0.9$ & 1.8 & 95 \\
Vitamin $B_{3}$ (mg/day) & $10.8 \pm 2.2$ & 19.8 & 50.5 \\
\hline
\end{tabular}

$(\mathrm{n}=205) *(24)$

All the subjects were males, the result of their mean anthropometric parameter in table 5 shows that their mean age was 32.81 years and ranges between 22 years to 52 years. The mean weight was $64.8 \mathrm{~kg}$ while their mean height was $1.71 \mathrm{~m}$.

Table 5: Anthropometric parameters of the road transport workers.

\begin{tabular}{ll}
\hline Parameters & Mean+SD \\
\hline Age (years) & $32.81 \pm 9.1$ \\
Weight $(\mathrm{kg})$ & $64.80 \pm 11.5$ \\
Height $(\mathrm{m})$ & $1.71 \pm 0.8$ \\
BMI $\left(\mathrm{kg} / \mathrm{m}^{2}\right)$ & $21.91 \pm 3.2$ \\
\hline
\end{tabular}

The nutritional status result in table 6 shows that $30.8 \%$ were underweight, $18.5 \%$ were overweight, while $3.9 \%$ were obese with BMI $>30.0 \mathrm{~kg} / \mathrm{m}^{2}$.

Table 6: Nutritional status of road transport workers.

\begin{tabular}{lll}
\hline Nutritional status & $\mathbf{n}$ & \% \\
\hline Underweight & 63 & 30.8 \\
Normal & 96 & 46.8 \\
Overweight & 38 & 18.5 \\
Obese & 8 & 3.9 \\
\hline
\end{tabular}




\section{Discussion}

This trend of high consumption of alcohol and smoking was common among all the transport road workers as most of them were teenagers and young adults. This is in agreement with the works of McPhillips et al $[1994]^{(1)}$ who said that cigarette smoking is a highly pervasive personal habit, with a strong appeal among teenagers and young adults. For centuries, smokers and alcoholics often perceived that these substances relieve feelings of stress, depression, a sense of belonging, increase confidence and mental concentration ${ }^{(2,3)}$. Some of these subjects were alcoholic abusers in conjunction with smoking of Indian hemp, a narcotic drug that may result in social nuisance with criminal tendencies. This correlates with earlier studies which have shown that smoking and alcoholism are social insolence which are predictor to household violence, divorce, various crimes and juvenile delinquencies ${ }^{(3,4)}$.

According to this study, none of the subjects have the knowledge that smoking can impair appetite or nutrient intake, and bioavailability of nutrients during the interview. This might be one of the reasons why their daily energy intake was lower (2029kcal) than RDA (2900kcal) meeting only $70 \%$ of their daily requirement. Another reason is the fact that alcohol significantly affects the intake of carbohydrate, an energy giving nutrient. Although their daily protein intake met over $100 \%$ of their RDA ( $81.75 \mathrm{~g} /$ day). There was no significant effect $(\mathrm{P}>0.05)$ of alcohol and cigarette smoking on nutrients such as calcium and iron. Studies had shown that cigarette smoking and alcohol consumption impair nutrient and energy intake. Even micronutrients such as thiamine, $\mathrm{B}_{2}$ and niacin are usually impaired ${ }^{(14,15)}$.

Smoking and alcohol consumption affect energy intake, nutrients intake and significantly affect their body mass index (BMI) at $(\mathrm{P}<0.05)$. The nutritional status result (table 6) shows that $30.8 \%$ were underweight, $18.5 \%$ were overweight, while $3.9 \%$ were obese with BMI $>30.0 \mathrm{~kg} / \mathrm{m}^{2}$. This result is consistent with what was reported by Parlesak in his work on the effect of alcohol and smoking on nutritional status in $2002^{(14)}$.

\section{Conclusion}

It is evident from the result of this study that alcohol, alcoholic beverages consumption, and cigarette smoking interfered with nutrients intake, changing body weight, and basal metabolic rate. Cigarette smoking and alcohol consumption impaired appetite, nutrient utilization and bioavailability, energy intake and bring about future health problems.

\section{Recommendation}

Therefore, the intake of alcohol, alcoholic beverages and cigarette smoking demand public health concern because cigarette smoking and alcohol are risk factors for many chronic diseases in later stage of life. It is also a major cause of road accidents among highway drivers. Both alcohol and smoking had been known to contribute to society and household violence globally. It is on this inference that government and other stakeholders should provide legislation against selling and purchasing, and drinking of narcotics such as cigarette and alcohol in public motor parks and do everything necessary to ensure compliance.

\section{References}

[1] McPhillips JB, Eaton CB, Gans KM, Derby CA, Lasater TM, McKenny JL, and Carlton RA (1994). Dietary differences in smokers and non-smokers from two southeastern New England communities. J Am Diet Assoc. 94(3):287-292.

[2] Parrott, A.C. (1999). Does cigarette smoking causes stress? American Psychologist 5\{10):817.

[3] Fisher M, and Gordon T (1985). The relation of drinking and smoking habits to diet: the Lipid. Research Clinics Prevalence Study. Am J Clin Nutr. 41:623-630

[4] Faulkner RA, Bailey DA, and Mirwald RL (1987). The relationship of physical activity to smoking characteristics in Canadian men and women. Can J Pub Health. 78:155-160

[5] WHO (2008). Report on global tobacco epidemic: World Health Organization Geneva, Switzerland.

[6] WHO (2009). Prevalence of current tobacco use among adults aged 15 years. World Health Organization Geneva, Switzerland.

[7] Leo, M.A., Arai, M., Sato, M. and Lieber, C.S. (1982). Effects of hepatic vitamin A depletion on the liver in humans and rats. Gastroenterology 84:562-572.

[8] NCHS United States Public Health Services (1976). Health resources administration. Growth charts. Rockville, MD, USA: National Centre for Health Services.

[9] WHO (1983). Measuring Change in Nutritional Status. National Centre for Health Statistics (NCHS), WHO, Geneva.

[10] Platt, B.S. (1975). Tables of representative values of foods commonly used in tropical countries. Medical research council special report series No. 302. ( $7^{\text {th }}$ Impression) HMSO, London, pp.46

[11] 11.FAO/WHO/UNU (1985). Energy and protein requirements. World Health Organization Tech Rept. Series, 724.

[12] 12.Juergen E (2007). NutriSurvey for Windows. SEAMEO-TROPMED RCCN- University of Indonesia.

[13] 13.Oguntona EB, and Akinyele IO (1981). Nutrient composition of commonly eaten foods in Nigeria- raw, processed and prepared. Food Basket Foundation Publication Series OBT printing ventures, Ibadan.

[14] 14. Parlesak, A. (2002). Gastric alcohol dehydrogenase in man: Influence of gender, age, alcohol consumption and smoking in a Caucasian population. Alcohol. 37:338.

[15] 15. Adibi, S.A., Baraona, E. and Lieber, C.S. (1992). Effects of ethanol on amino acids and protein metabolism. New York: Plenum Press, pp127-155.

[16] 16. Adhikari, B., Kahende, J., Malarcher, T., Tong, V. (2008). Smoking attributable mortality, years of potential life lost, and productivity losses. 57(45):1226-8. 
[17] 17. Dechanet, C., Anahory, T., Mathieu, D.J.C., Quantin, X., Reythman, L., Hamama, H.B., Dechaud, H. (2010). Effects of cigarette smoking on reproduction. Human reproduction update 17(1):76.

[18] 18. Doll, R., Peto, R., Boreham, J. and Sutherland, I. (2004). "Mortality in relation to smoking- 50 years observation on male British doctors".

[19] 19. Guidon, G.E. and Boisclair, D. (2003). Past, current and future trends in tobacco use. Washington DC: The International Bank for Recommendation and Development/The World Bank pp13-16.

[20] 20. Mamun, A.A., Peeters, A., Barendregt, J., Willeken, F., Nusselder, W., Bonneux, L.F., Nedcom, T.N.E., Group, D.C.O.M.R. (2004). "Smoking decreases the duration of life with and without cardiovascular disease". European Heart Journal 25(5):409.

[21] 21. Naomi, O. and Erik, M.C. (2010). Marchant of doubt; How a handful of scientists obscured the truth on issues from tobacco smoke to global warming. Bloom press, p15.

[22] 22. Pell, J., Haw, S., Cobbe, S., Newly, D., Pell, A., Fischbacher, C. et al (2008). Smoke free legislation and hospitalizations for acute coronary syndrome. The New England Journal of Medicine 359(5):480-491.

[23] 23.Schuckit, M. (2004). Alcohol and alcoholism. In: Kasper D. and others, eds. Harrison's principles of internal medicine. New York, Mc Graw-Hill.

[24] 24.FAO/WHO/UNU (1985). Micronutrients' requirements. World Health Organization Tech Rept. Series, 724. 